\title{
Participación de los virus respiratorios en la neumonía del adulto inmunocompetente adquirida en la comunidad
}

\author{
FERNANDO SALDÍAS PEÑAFIEL ${ }^{1}$, MARCOS ORTEGA GUTIÉRREZ ${ }^{1}$, GINO \\ FUENTES LÓPEZ ${ }^{2}$, JOSÉ MANUEL ELOLA ARÁNGUIZ ${ }^{\mathrm{a}}$, JAVIER URIBE \\ MONASTERIO ${ }^{a}$, ARTURO MORALES SOTO ${ }^{1}$, ORLANDO DÍAZ PATIÑO ${ }^{1}$
}

\section{Importance of respiratory virus in immunocompetent adult patients hospitalized with community-acquired pneumonia}

Background: Community-acquired pneumonia (CAP) is a relevant worldwide cause of morbidity and mortality in adult population, however its etiology is often not identified and therapy is empirical. Aim: To assess the etiology of CAP in immunocompetent adult hospitalized patients using conventional and molecular diagnostic methods. Material and Methods: We prospectively studied 240 adult patients who were hospitalized for CAP to identify the microbial etiology. Sputum and blood cultures were obtained as well as serology testing for Mycoplasma pneumoniae and Chlamydophila pneumoniae, urinary antigen testing for Legionella pneumophila and Streptococcus pneumoniae, and a nasopharyngeal swab for the detection of sixteen respiratory viruses by reverse transcriptase polymerase chain reaction (RT-PCR). Results: In 100 patients $(41.7 \%)$ a single respiratory pathogen was identified. In 17 (7.1\%) cases, a mixed bacterial and viral infection was detected and no pathogen was identified in 123 cases (51\%). The most commonly identified pathogens identified were: influenza virus (15.4\%), parainfluenza virus (10.8\%), rhinovirus (5\%), Streptococcus pneumoniae (5\%), respiratory syncytial virus (2.9\%) and Mycoplasma pneumoniae $(2.5 \%)$. Infectious agent detection by RT-PCR provided greater sensitivity than conventional techniques. Viral respiratory infections were more prevalent in older patients with comorbidities and high risk patients, according to the Fine index at hospital admission. The clinical severity and outcome were independent of the etiological agents detected. Conclusions: The use of molecular diagnostic techniques expanded the detection of respiratory viruses in immunocompetent adults hospitalized with CAP.

(Rev Med Chile 2016; 144: 1513-1522)

Key words: Molecular Diagnostic Techniques; Pneumonia; Pneumonia, Viral.

a neumonía adquirida en la comunidad (NAC) constituye una causa frecuente de consulta ambulatoria, hospitalización y muerte, especialmente en el adulto mayor con
'Departamento de Enfermedades Respiratorias, Facultad de Medicina, Pontificia Universidad Católica de Chile, Santiago, Chile. ${ }^{2}$ Facultad de Medicina, Universidad Austral de Chile, Valdivia. Chile.

alnterno de Medicina, Facultad de Medicina, Pontificia Universidad Católica de Chile. Santiago, Chile.

Fuente de financiamiento: Proyecto Interdepartamental de la Facultad de Medicina, Pontificia Universidad Católica de Chile.

Recibido el 15 de julio de 2016, aceptado el 19 de noviembre de 2016.

Correspondencia a:

Dr. Fernando Saldías Peñafiel Departamento de Enfermedades Respiratorias, División de Medicina, Facultad de Medicina Pontificia Universidad Católica de Chile.

Marcoleta 350, Santiago, Chile. Teléfonos: (562) 26331541 (562) 23543242

Fax: (562) 26335255

fsaldias@med.puc.cl comorbilidad múltiple ${ }^{1-3}$. En nuestro país, la neumonía es la primera causa de muerte de origen infeccioso y la séptima causa específica de muerte, con una tasa de mortalidad de 18 casos por 100.000 
habitantes ${ }^{4}$. La neumonía comunitaria representa un importante problema de salud pública, considerando su elevada prevalencia, demanda de recursos de salud y letalidad ${ }^{1-3}$. La mortalidad específica por esta causa ha disminuido sustancialmente en los últimos diez años en nuestro país ${ }^{4}$, probablemente asociado al incremento en la oferta de servicios sanitarios, la disponibilidad de mejores métodos de diagnóstico y tratamientos farmacológicos más efectivos. En Chile, la mayoría de los estudios han sido realizados en pacientes adultos hospitalizados por neumonía, en quienes se concentra el mayor riesgo de complicaciones y muerte ${ }^{5-18}$. Durante los últimos años se ha avanzado en forma importante en el diagnóstico ${ }^{12,13}$, evaluación de la gravedad ${ }^{5-10,15,16}$, estudio de la etiología ${ }^{10,11,17,18}$ y tratamiento ${ }^{5,9,10,14}$ del paciente adulto con neumonía comunitaria.

Los exámenes microbiológicos permiten identificar el agente causal de la neumonía y su patrón de sensibilidad a los antibióticos ${ }^{19-22}$. El tratamiento antimicrobiano dirigido contra un patógeno conocido permite reducir el espectro de acción de los fármacos, los costos del tratamiento, el riesgo de reacciones adversas y el desarrollo de resistencia antibiótica. El riesgo de complicaciones y muerte de los enfermos hospitalizados por neumonía comunitaria justifica la realización de exámenes microbiológicos básicos que intentarán precisar el agente causal de la infección pulmonar y orientar el tratamiento antimicrobiano específico ${ }^{19-22}$.

En la situación clínica ideal, el tratamiento antimicrobiano empírico prescrito en la neumonía comunitaria del adulto debería estar basado en el resultado de los estudios microbiológicos realizados en el medio nacional ${ }^{19-22}$. La información disponible sobre la etiología de la neumonía en el ámbito ambulatorio es escasa en Chile, en comparación con el medio intrahospitalario ${ }^{5,6,10,11,17,18}$. En los estudios diseñados específicamente para estudiar los agentes causales, en 40-50\% de los casos no se logra identificar el patógeno respiratorio, lo que pone de manifiesto las limitaciones de sensibilidad y especificidad de los métodos diagnósticos tradicionales (Gram y cultivo de expectoración, sangre y líquido pleural, serología de microorganismos atípicos, técnicas de inmunofluorescencia de virus respiratorios). Las nuevas técnicas de biología molecular (ej: reacción en cadena de la polimerasa en tiempo real) aplicadas a muestras respiratorias han mejorado significativamente el rendimiento diagnóstico en los pacientes adultos con infección del tracto respiratorio inferior ${ }^{23,24}$.

El propósito de este estudio es evaluar la participación de los virus respiratorios en la etiología de la neumonía comunitaria de gravedad moderada $y$ alta en el paciente adulto inmunocompetente hospitalizado en la sala de cuidados generales y unidad de cuidados intensivos del Hospital Clínico de la Pontificia Universidad Católica de Chile.

\section{Material y Métodos}

En un estudio clínico descriptivo prospectivo, se evaluaron 240 pacientes adultos hospitalizados por un episodio de neumonía adquirida en la comunidad en el Hospital Clínico de la Pontificia Universidad Católica de Chile, entre el 1 de junio de 2014 y 31 de diciembre de 2015. Criterios de inclusión: adultos inmunocompetentes mayores de 18 años que cumplían los criterios diagnósticos de neumonía comunitaria descritos por Fang y $\mathrm{cols}^{25}$ que aceptaron participar en el estudio previa firma del consentimiento informado. Se excluyeron del estudio los pacientes portadores del virus de inmunodeficiencia humana, tumores sólidos o hematológicos diagnosticados en los últimos cinco años o en quimioterapia, neutropenia (menos de 1.000 células $/ \mathrm{mm}^{3}$ ) y tratamiento quimioterápico o inmunosupresor en los seis meses previos a la admisión al hospital. En el período del estudio se enroló al $80 \%$ de los pacientes hospitalizados por neumonía adquirida en la comunidad que cumplían los criterios de inclusión del protocolo. Las características clínicas y sociodemográficas de los pacientes que no fueron enrolados eran similares a la cohorte estudiada. El estudio clínico fue aprobado por el Comité de Ética de la Facultad de Medicina de la Pontificia Universidad Católica de Chile.

\section{Exámenes microbiológicos}

En los pacientes con neumonía comunitaria hospitalizados se solicitaron los siguientes exámenes microbiológicos: a) Tinción de Gram y cultivo de expectoración; b) Hemocultivos aerobios; c) Tinción de Gram y cultivo de líquido pleural. La identificación de los agentes microbianos y los estudios de susceptibilidad se realizaron según métodos convencionales ${ }^{26}$. Se usaron los puntos de corte de susceptibilidad antibiótica de las cepas de Streptococcus pneumoniae publicados por NCCLS 
en $2008^{27}$. La solicitud de los siguientes exámenes quedó a discreción del médico tratante, basados en las características epidemiológicas, evolución y gravedad del caso particular; d) Antígeno urinario de Streptococcus pneumoniae y Legionella pneumophila serotipo 1; e) Determinación de inmunoglobulinas $\mathrm{G}$ y M séricas de Mycoplasma pneumoniae y Chlamydophila pneumoniae en la admisión al hospital y seguimiento a 30 días mediante técnica de inmunofluorescencia indirecta. El diagnóstico de infección por microorganismos atípicos estuvo basado en la seroconversión, definida por un aumento de cuatro veces en los títulos de anticuerpos entre los sueros pareados, o en los pacientes que sólo se disponía de suero en la fase aguda por la presencia de un título de $\operatorname{IgM} \geq 1 / 32$ para M. pneumoniae y $\geq 1 / 16$ para C. pneumoniae.

En los pacientes enrolados en el protocolo se tomaron muestras de hisopado nasofaríngeo para la búsqueda de los virus influenza A y B, parainfluenza 1, 2, 3 y 4, virus sincicial respiratorio A y $\mathrm{B}$, adenovirus, metapneumovirus, rhinovirus, coronavirus NL63/229E/OC43, enterovirus y bocavirus. Se empleó la técnica de reacción en cadena de la polimerasa con transcriptasa inversa (RT-PCR) para la detección de antígenos virales específicos (Seeplex RV15 ACE Detection, Seegene, USA).

\section{Información clínica}

En los pacientes ingresados al protocolo se registraron los siguientes antecedentes clínicos: edad, sexo, comorbilidades, consumo de tabaco y alcohol, uso de antibióticos previo a la hospitalización, lugar de procedencia (hogar, centro geriátrico), sospecha de aspiración bronquial (definida como cualquier condición clínica subyacente asociado a compromiso de conciencia, pérdida del reflejo tusígeno o alteración de la deglución), cuadro clínico de presentación y la presencia de alguna enfermedad aguda concomitante (insuficiencia cardiaca, arritmia, isquemia miocárdica, asma bronquial o enfermedad pulmonar obstructiva crónica reagudizada). Además, se consignó el lugar de manejo (sala de cuidados generales, unidad de cuidado intermedio o cuidados intensivos), los signos vitales y exámenes de laboratorio solicitados en la admisión al hospital (hemograma, proteína $\mathrm{C}$ reactiva, gases arteriales, glicemia, radiografía de tórax, albúmina sérica, electrolitos plasmáticos, nitrógeno ureico y creatinina plasmática) que fueron empleados en el cálculo de los índices de gravedad descritos por Fine y cols. (PSI score) $)^{28} \mathrm{y}$ la Sociedad Británica de Tórax (CURB-65) ${ }^{29}$.

Durante la estadía en el hospital se consignaron los tratamientos antimicrobianos y la aparición de las siguientes complicaciones: admisión a UCI, uso de ventilación mecánica, arritmias, insuficiencia cardiaca congestiva, isquemia miocárdica, accidente vascular encefálico, insuficiencia renal aguda, shock séptico, empiema pleural e infección extrapulmonar. La estadía y la sobrevida en el hospital y en el seguimiento a 30 días después de la admisión se obtuvieron de los registros clínicos.

\section{Análisis estadístico}

Los resultados fueron expresados como valores promedio \pm desviación estándar para las variables medidas en escala numérica y en porcentaje para las medidas en escala nominal. Las variables cualitativas (antecedentes clínico-radiográficos, etiología, evolución clínica y letalidad) fueron comparadas mediante la prueba de Chi cuadrado y el test exacto de Fisher, y las variables continuas con la prueba t de Student. Para ello se utilizó el programa SPSS versión 23.0. Las diferencias entre las variables fueron consideradas significativas con un valor de $\mathrm{p}<0,05$.

\section{Resultados}

En el período del estudio, se evaluaron 240 pacientes adultos hospitalizados por neumonía adquirida en la comunidad en el Hospital Clínico de la Pontificia Universidad Católica de Chile, en la Tabla 1 se describen las características sociodemográficas y clínicas de la cohorte, edad media: $71 \pm 18$ años (rango: $18-102$ ), 50\% varones, $82,9 \%$ tenía comorbilidades, especialmente enfermedades cardiovasculares, respiratorias, metabólicas y neurológicas crónicas; un tercio había recibido tratamiento antibiótico antes de la admisión al hospital, dos tercios correspondían a las categorías de riesgo IV-V de Fine, la mitad fueron manejados en unidades de cuidados intermedios e intensivo, la estadía media en el hospital fue 7,5 días (rango: 2-44), 3,3\% fallecieron en el hospital y $5,4 \%$ en el seguimiento a 30 días. Los principales antimicrobianos prescriptos en la admisión al hospital fueron cefalosporinas de tercera generación $(86,3 \%)$ asociados a fluoroquinolonas $(41,3 \%)$ o macrólidos $(3,3 \%)$.

El rendimiento diagnóstico de los exámenes 
Tabla 1. Características clínicas de los pacientes adultos inmunocompetentes hospitalizados por neumonía adquirida en la comunidad

\begin{tabular}{|c|c|c|}
\hline Variables & n (media $\pm \mathrm{DE}$ ) & $\%$ - Rango \\
\hline $\mathrm{n}$ & 240 pacientes & \\
\hline Edad (años) & $71,4 \pm 18,0$ & $18-102$ \\
\hline Género (Masculino-Femenino) & $119-121$ & $49,6-50,4$ \\
\hline Lugar de admisión (Sala-Intermedio-UCI) & $120-92-28$ & $50-38-12$ \\
\hline Comorbilidades & 199 & 82,9 \\
\hline Enfermedad cardiovascular & 92 & 38,3 \\
\hline Enfermedad Pulmonar Obstructiva Crónica & 46 & 19,2 \\
\hline Diabetes mellitus & 61 & 25,4 \\
\hline Enfermedad neurológica crónica & 46 & 19,2 \\
\hline Enfermedad renal crónica & 34 & 14,2 \\
\hline Asma bronquial & 20 & 8,3 \\
\hline Hospitalización últimos 12 meses & 52 & 21,7 \\
\hline Autovalente-Postrado & $197-26$ & $82,1-10,8$ \\
\hline Consumo de tabaco & 76 & 31,7 \\
\hline Uso previo de antibióticos & 84 & 35,0 \\
\hline Duración de los síntomas (días) & $7,4 \pm 7,9$ & $1-30$ \\
\hline Fiebre & 157 & 65,4 \\
\hline Escalofríos & 37 & 15,4 \\
\hline Tos & 204 & 85,0 \\
\hline Expectoración & 151 & 62,9 \\
\hline Dolor torácico & 62 & 25,8 \\
\hline Disnea & 178 & 74,2 \\
\hline Compromiso de conciencia & 54 & 22,5 \\
\hline Sospecha de aspiración & 19 & 7,9 \\
\hline Neumonía multilobar & 76 & 31,7 \\
\hline Derrame pleural & 30 & 12,5 \\
\hline Duración de la hospitalización (días) & $7,5 \pm 6,5$ & $2-44$ \\
\hline Índice de Fine (score PSI) & $108 \pm 43$ & $5-242$ \\
\hline Categorías de riesgo IV-V & 156 & 65,0 \\
\hline CURB-65 & $2,1 \pm 1,2$ & $0-5$ \\
\hline CURB-65 $\geq 2$ puntos & 160 & 66,6 \\
\hline Uso de ventilación mecánica & 20 & 8,3 \\
\hline Complicaciones en el hospital & 155 & 64,6 \\
\hline Letalidad en el hospital & 8 & 3,3 \\
\hline Letalidad en el seguimiento a 30 días & 13 & 5,4 \\
\hline
\end{tabular}


microbiológicos fue el siguiente: $26 \%$ para la tinción de Gram y cultivo de expectoración, 4,8\% para los hemocultivos, $14 \%$ para la serología de Mycoplasma pneumoniae y Chlamydophila pneumoniae, 5,5\% para los antígenos urinarios de $S$. pneumoniae y Legionella pneumophila, y 36,7\% para la técnica de RT-PCR de virus respiratorios. Se logró identificar el agente causal de la neumonía en 117 pacientes, en 100 casos hubo infección monomicrobiana $(41,7 \%)$ y en 17 casos infección polimicrobiana $(7,1 \%)$; no se logró identificar el agente causal en 123 pacientes $(51,2 \%)$ (Tabla 2). Los principales microorganismos aislados fueron los virus respiratorios $(37,1 \%)$ : virus influenza (15,4\%), virus parainfluenza serotipos 1-4 $(10,8 \%)$, rinovirus $(5 \%)$, virus sincicial respiratorio $(2,9 \%)$, metapneumovirus $(2,1 \%)$, enterovirus $(1,7 \%)$ y coronavirus OC43 $(0,8 \%)$; y las bacterias clásicas (15\%): Streptococcus pneumoniae (5\%), Mycoplasma pneumoniae (2,5\%), Haemophilus influenzae (2,1\%), Klebsiella pneumoniae (1,7\%), Staphylococcus aureus $(1,7 \%)$ y un grupo misceláneo $(4,6 \%)$ (Tabla 3$)$. Las cepas de S. pneumoniae aisladas eran sensibles a penicilina y cefotaxima, $y$ un tercio eran resistentes a macrólidos. Sólo una de las cinco cepas de $H$. influenzae era productora de beta-lactamasa.

Las infecciones respiratorias por virus influenza se concentraron en los meses de invierno (junio-agosto), por virus parainfluenza en invierno y primavera (julio-noviembre), por rinovirus en otoño, invierno y primavera (mayo-octubre), y las infecciones respiratorias bacterianas y de causa desconocida se distribuyeron en las cuatro estaciones, especialmente durante los meses de otoño e invierno (Figura 1).

Las manifestaciones clínicas y radiográficas fueron similares en la infección pulmonar ocasionada por virus respiratorios, bacterias y de causa desconocida; sin embargo, las infecciones respiratorias de origen viral se presentaron en sujetos de edad más avanzada $(76 \pm 15$ vs $66 \pm 20$ y $70 \pm 18$ años respectivamente, $\mathrm{p}<0,05)$, predominaron en mujeres ( $60 \%$ vs $36 \%$ y $47 \%$, p $<0,05)$, correspondieron a las categorías IV y V de Fine $(79 \%$ vs $61 \%$ y $57 \%, \mathrm{p}<0,05)$ o CURB- $65 \geq 2$ puntos (79\% vs $63 \%$ y $59 \%$, p < 0,05) en la admisión al hospital y la estadía en el hospital fue más breve que en la infección pulmonar bacteriana ( $8 \pm 6,5 \mathrm{vs}$ $11 \pm 9$ días, $\mathrm{p}<0,05)$. La presencia de hipoxemia $(61 \%$ vs $52 \%$ y $40 \%, p<0,05)$ y nitrógeno ureico
Tabla 2. Etiología de la neumonía adquirida en la comunidad en el adulto inmunocompetente hospitalizado

\begin{tabular}{|lrc|}
\hline Etiología de la neumonía & n & \% \\
\hline Infección monomicrobiana & 100 & 41,7 \\
Virus respiratorios & 76 & 31,7 \\
Bacterias & 24 & 10,0 \\
Infección polimicrobiana & 17 & 7,1 \\
Virus + Bacterias & 8 & 3,3 \\
Dos o más virus & 5 & 2,1 \\
Dos o más bacterias & 4 & 1,7 \\
Desconocida & 123 & 51,2 \\
\hline
\end{tabular}

Tabla 3. Microorganismos aislados en adultos inmunocompetentes hospitalizados por neumonía adquirida en la comunidad

\begin{tabular}{|lcc|}
\hline Microorganismos & $\mathbf{n}$ & $\mathbf{\%}$ \\
Virus respiratorios & $\mathbf{8 9}$ & $\mathbf{3 7 , 1}$ \\
& $\begin{array}{c}\text { pacientes } \\
\text { Influenza A y B }\end{array}$ & \\
Parainfluenza 1-2-3-4 & $35-2$ & $14,6-0,8$ \\
Rhinovirus spp & 12 & $1,3-2,9-6,3-0,4$ \\
Virus sincicial respiratorio & & 5,0 \\
A y B & $3-4$ & $1,3-1,7$ \\
Metapneumovirus & 5 & 2,1 \\
Enterovirus & 4 & 1,7 \\
Coronavirus Oc43 & 2 & 0,8 \\
Bacterias & $\mathbf{3 6}$ & $\mathbf{1 5 , 0}$ \\
Streptococcus pneumoniae & 12 & \\
Mycoplasma pneumoniae & 6 & 2,0 \\
Haemophilus influenzae & 5 & 2,1 \\
Klebsiella pneumoniae & 4 & 1,7 \\
Staphylococcus aureus & 4 & 1,7 \\
Pseudomonas aeruginosa & 3 & 1,3 \\
Escherichia coli & 2 & 0,8 \\
Moraxella catarrhalis & 1 & 0,4 \\
Chlamydophila pneumoniae & 1 & 0,4 \\
Legionella pneumophila & 1 & 0,4 \\
Proteus mirabilis & 1 & 0,4 \\
Enterococcus faecium & 1 & 0,4 \\
Burkholderia cepacia & 1 & 0,4 \\
Desconocida & $\mathbf{1 2 3}$ & $\mathbf{5 1 , 2}$ \\
\hline
\end{tabular}




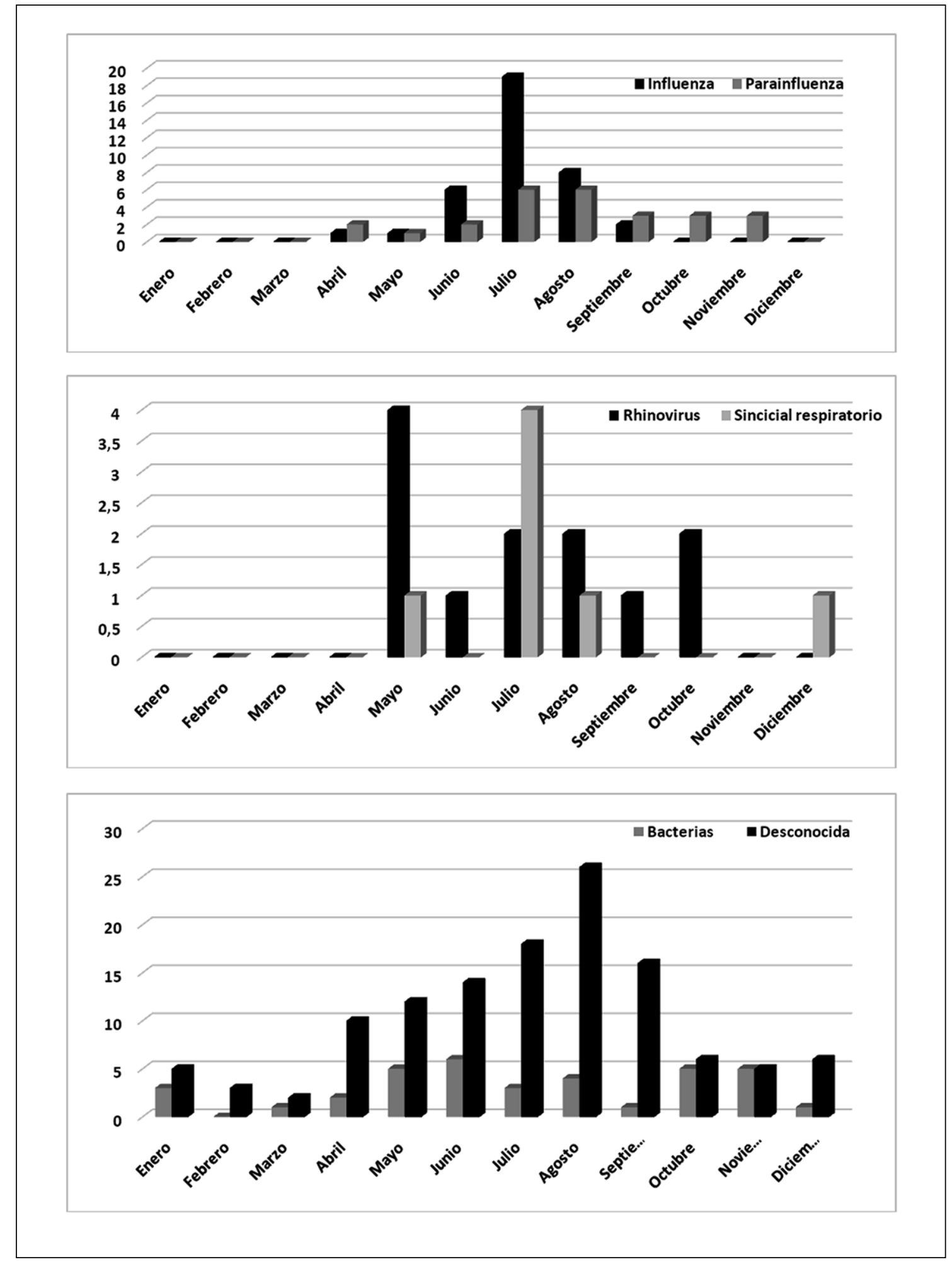

Figura 1. Patrón estacional de las infecciones respiratorias del adulto según agente causal. 
sérico elevados ( $61 \%$ vs $44 \%$ y $43 \%$, p < 0,05$)$ en la admisión al hospital fueron más frecuentes en las infecciones respiratorias virales. El recuento de leucocitos, neutrófilos y la proteína $\mathrm{C}$ reactiva sérica medidos en la admisión al hospital fueron más elevados en las infecciones bacterianas o de causa desconocida que en las infecciones virales $(\mathrm{p}<0,05)$. La tasa de admisión a UCI, conexión a ventilación mecánica, complicaciones en el hospital y letalidad en el hospital y seguimiento a 30 días fueron similares en las tres categorías diagnósticas.

\section{Discusión}

Los principales hallazgos del estudio fueron: 1) Los principales microorganismos aislados en adultos inmunocompetentes hospitalizados por neumonía adquirida en la comunidad fueron los virus respiratorios, especialmente virus influenza, parainfluenza y rinovirus; 2) El cuadro clínico-radiográfico fue similar en las infecciones respiratorias virales, bacterianas y de causa desconocida; c) Las infecciones respiratorias virales se presentaron en pacientes de edad avanzada, con comorbilidad múltiple y criterios de gravedad en la admisión al hospital; d) Los parámetros inflamatorios elevados en la admisión al hospital predominaron en las infecciones respiratorias bacterianas y de causa desconocida; e) El riesgo de complicaciones, admisión a UCI y letalidad en el hospital fueron similares en las infecciones respiratorias virales, bacterianas y de causa desconocida.

Los principales microorganismos aislados en el adulto inmunocompetente hospitalizado por neumonía comunitaria fueron el virus influenza, virus parainfluenza, rhinovirus, Streptococcus pneumoniae, virus sincicial respiratorio y $M y$ coplasma pneumoniae. Las técnicas de biología molecular han facilitado la identificación de los virus respiratorios y microorganismos atípicos en las infecciones respiratorias de la población adulta $^{23,24}$. En la Tabla 4 se describen los principales microorganismos aislados en el paciente adulto hospitalizado por neumonía adquirida en la comunidad en nuestro país ${ }^{10,11,17,18}$, donde destacan Streptococcus pneumoniae, los virus respiratorios, los microorganismos atípicos (M. pneumoniae, C. pneumoniae y Legionella spp) y un grupo misceláneo que incluye bacilos Gram negativos y Staphylococcus aureus. No se logró identificar el agente causal de la infección pulmonar en $35-70 \%$ de los casos.

Tabla 4. Etiología de la neumonía adquirida en la comunidad en la población adulta en Chile ${ }^{10,11,17,18}$

\begin{tabular}{|lcccc|}
\hline Microorganismos & Riquelme & Díaz & Luchsinger & Arancibia \\
\hline N & 200 & 176 & 356 & 104 \\
\hline S. pneumoniae & $12 \%$ & $27,8 \%$ & $21,1 \%$ & $26 \%$ \\
\hline H. influenzae & $7 \%$ & $4 \%$ & $0,8 \%$ & $1,9 \%$ \\
\hline M. pneumoniae & $1 \%$ & $2,8 \%$ & $9 \%$ & $5,8 \%$ \\
\hline C. pneumoniae & $5 \%$ & $3,4 \%$ & $7,9 \%$ & $3,8 \%$ \\
\hline L. pneumophila & $1,5 \%$ & $2,3 \%$ & $3,7 \%$ & $8,7 \%$ \\
\hline Gram negativos & $4 \%$ & $2,8 \%$ & $3,1 \%$ & $2,9 \%$ \\
\hline S. aureus & $3,5 \%$ & $0,6 \%$ & $2,2 \%$ & $2,9 \%$ \\
\hline Virus influenza & $\mathrm{NE}$ & $6,3 \%$ & $7,6 \%$ & $2,9 \%$ \\
\hline Virus parainfluenza & $\mathrm{NE}$ & $9,7 \%$ & $0 \%$ & $0 \%$ \\
\hline Rhinovirus & $\mathrm{NE}$ & $\mathrm{NE}$ & $11,5 \%$ & $\mathrm{NE}$ \\
\hline Sincicial respiratorio & $\mathrm{NE}$ & $0,6 \%$ & $13,5 \%$ & $1,9 \%$ \\
\hline Adenovirus & $\mathrm{NE}$ & $1,7 \%$ & $0,8 \%$ & $0 \%$ \\
\hline Polimicrobiano & $5 \%$ & $7,4 \%$ & $16,9 \%$ & $4,8 \%$ \\
\hline Causa desconocida & $70,5 \%$ & $44,3 \%$ & $34,8 \%$ & $40,4 \%$ \\
\hline
\end{tabular}


En un estudio de vigilancia epidemiológica realizado en cinco hospitales de Chicago y Nashville, se evaluaron 2.320 pacientes adultos hospitalizados por neumonía adquirida en la comunidad, los principales microorganismos identificados fueron virus respiratorios (26\%), especialmente rhinovirus (9\%), virus influenza (6\%), metapneumovirus $(4 \%)$ y virus sincicial respiratorio (3\%), y entre las bacterias (14\%), destacan Streptococcus pneumoniae (5\%) y Mycoplasma pneumoniae $(2 \%)^{30}$; estos hallazgos concuerdan con nuestro estudio.

En un metaanálisis reciente que incluyó 23 estudios y 6.404 pacientes se estimó la incidencia de los virus respiratorios en pacientes adultos con neumonía comunitaria detectados mediante técnicas de reacción en cadena de la polimerasa (PCR), destacando los siguientes hallazgos: la incidencia de virus respiratorios en pacientes ambulatorios fue $10,2 \%$ (IC 95\% 7,3-13,1\%) y en pacientes hospitalizados fue 22,7\% (IC 95\% 19-26,4\%) y los principales patógenos respiratorios identificados fueron virus influenza $(8,9 \%)$, rinovirus $(6 \%)$, coronavirus $(4,7 \%)$, virus parainfluenza $(2,4 \%)$ y sincicial respiratorio $(2 \%)^{31}$.

Las limitaciones de sensibilidad y especificidad de los exámenes microbiológicos tradicionales solicitados en pacientes adultos hospitalizados por neumonía (Gram y cultivo de expectoración y líquido pleural, hemocultivos y serología de microorganismos atípicos), han determinado la búsqueda de nuevas técnicas basadas en la biología molecular que han facilitado la pesquisa de los agentes causales de las infecciones respiratorias en la población adulta, especialmente los virus respiratorios y microorganismos atípicos ${ }^{23,24,30,31}$.

Similar a lo descrito en otros estudios, el cuadro clínico-radiográfico y la evolución en el hospital fueron similares en las infecciones respiratorias virales, bacterianas y de causa desconocida ${ }^{32-36}$. Por este motivo, en las guías clínicas se establece que el cuadro clínico y los hallazgos en la radiografía de tórax no permiten precisar el agente causal de la neumonía ${ }^{19-22}$. En nuestro estudio, las infecciones respiratorias virales predominaron en adultos mayores de 65 años con comorbilidad múltiple, criterios de gravedad en la admisión al hospital, presencia de hipoxemia y disfunción renal aguda, y con parámetros inflamatorios menos elevados comparados con las infecciones respiratorias bacterianas o de causa desconocida.

En los países con climas templados, las infec- ciones por virus respiratorios presentan variaciones estacionales; de este modo, las infecciones respiratorias por virus influenza predominaron durante los meses de invierno en coincidencia con el apogeo estacional que dura alrededor de 6-8 semanas cada año, mientras que el virus parainfluenza se concentró en los meses de invierno y primavera, y el rinovirus en los meses de otoño, invierno y primavera. Los estudios de vigilancia epidemiológica en centros centinela confirman el patrón estacional de los virus respiratorios, destacando el comportamiento epidémico de los virus influenza y sincicial respiratorio durante los meses de invierno ${ }^{30,37,38}$.

La detección de virus respiratorios puede estar sobrerrepresentada en nuestra cohorte por varias razones: a) El período del estudio correspondió a 18 meses, incluyendo dos estaciones de invierno y primavera, lo cual puede explicar el aumento de la prevalencia de virus respiratorios de predominio estacional; b) Las nuevas técnicas de biología molecular de elevada sensibilidad y especificidad han facilitado la pesquisa de virus respiratorios; siendo menor el rendimiento de las técnicas microbiológicas convencionales (tales como la tinción Gram y cultivo de expectoración y líquido pleural, hemocultivos, serología de microorganismos atípicos) empleadas en nuestro estudio en la pesquisa de bacterias clásicas y microorganismos atípicos.

En conclusión, los exámenes microbiológicos basados en las técnicas de biología molecular en tiempo real han facilitado la identificación de los virus respiratorios como agentes causales de neumonía en la población adulta, información relevante en el manejo de los pacientes con infecciones respiratorias en el ámbito ambulatorio y hospitalario y en la confección de las guías de práctica clínica de nuestro país.

\section{Referencias}

1. Garibaldi RA. Epidemiology of community-acquired respiratory tract infections in adults: incidence, etiology, and impact. Am J Med 1985; 78: 32-7.

2. Almirall J, Bolıbar I, Vidal J, Sauca G, CollP, Niklasson B, et al. Epidemiology of community-acquired pneumonia in adults: a population-based study. Eur Respir J 2000; 15: 757-63.

3. Marston BJ, Plouffe JF, File TM Jr, Hackman BA, Salstrom SJ, Lipman HB, et al. Incidence of community-ac- 
quired pneumonia requiring hospitalization. Results of a population-based active surveillance Study in Ohio. The Community-Based Pneumonia Incidence Study Group. Arch Intern Med 1997; 157: 1709-18.

4. Programa de Infecciones Respiratorias Agudas (IRA), Departamento de Estadísticas e Información de Salud, Ministerio de Salud de Chile, 2016.

5. Saldías F, Mardónez JM, Marchesse M, Viviani P, Farías G, Díaz A. Neumonía adquirida en la comunidad en el adulto hospitalizado. Cuadro clínico y factores pronósticos. Rev Med Chile 2002; 130: 1373-82.

6. Saldías F, O`Brien A, Gederlini A, Farías G, Díaz A. Neumonía adquirida en la comunidad en el anciano inmunocompetente que requiere hospitalización. Cuadro clínico, factores pronósticos y tratamiento. Arch Bronconeumol 2003; 39: 333-40.

7. Saldías F, Farías G, Villarroel L, Valdivia G, Mardónez JM, Díaz A. Diseño de un índice pronóstico clínico para el manejo de la neumonía del adulto adquirida en la comunidad. Rev Med Chile 2004; 132: 1037-46.

8. Díaz A, Álvarez M, Callejas C, Rosso R, Schnettler K, Saldías F. Cuadro clínico y factores pronósticos de la neumonía comunitaria grave en adultos hospitalizados en la Unidad de Cuidados Intensivos. Arch Bronconeumol 2005; 41: 20-6.

9. Gil R, Undurraga A, Saldías F, Jiménez P, Barros M, GENSER. Estudio multicéntrico de factores pronósticos en adultos hospitalizados por neumonía adquirida en la comunidad. Rev Med Chile 2006; 134: 1357-66.

10. Riquelme R, Riquelme M, Rioseco ML, Gómez V, Gil $\mathrm{R}$, Torres A. Etiología y factores pronósticos de la neumonía adquirida en la comunidad en el adulto hospitalizado, Puerto Montt, Chile. Rev Med Chile 2006; 134: 597-605.

11. Díaz A, Barría P, Niederman M, Restrepo MI, Dreyse J, Fuentes G, Couble B, et al. Etiology of community-acquired pneumonia in hospitalized patients in Chile: the increasing prevalence of respiratory viruses among classic pathogens. Chest 2007; 131: 779-87.

12. Saldías F, Cabrera D, de Solminihac I, Hernández P, Gederlini A, Díaz A. Valor predictivo de la historia clínica y examen físico en el diagnóstico de la neumonía del adulto adquirida en la comunidad. Rev Med Chile 2007; 135: 143-52.

13. Saldías F, Méndez JI, Ramírez D, Díaz O. Valor predictivo de la historia clínica y el examen físico en el diagnóstico de la neumonía del adulto adquirida en la comunidad. Revisión de la literatura. Rev Med Chile 2007; 135: 517-28.

14. Sanhueza LM, Vásquez C, Sepúlveda F, Barahona F, González R, Saldías F. Evaluación y manejo del adulto inmunocompetente hospitalizado por neumonía adquirida en la comunidad, en un hospital de baja complejidad, basado en la Guía Clínica Chilena. Rev Med Chile 2009; 137: 1283-90.

15. Saldías F, Viviani P, Pulgar D, Valenzuela F, Paredes S, Díaz O. Factores pronósticos, evolución y mortalidad en el adulto inmunocompetente hospitalizado por neumonía neumocócica adquirida en la comunidad. Rev Med Chile 2009; 137: 1545-52.

16. Saldías F, Díaz O. Índices predictores de eventos adversos en el adulto inmunocompetente hospitalizado por neumonía neumocóccica adquirida en la comunidad. Rev Chil Infect 2011; 28: 303-9.

17. Luchsinger V, Ruiz M, Zunino E, Martínez MA, Machado C, Piedra PA, et al. Community-acquired pneumonia in Chile: the clinical relevance in the detection of viruses and atypical bacteria. Thorax 2013; 68: 1000-6.

18. Arancibia F, Cortés CP, Valdés M, Cerda J, Hernández A, Soto L, et al. Importance of Legionella pneumophila in the etiology of severe community-acquired pneumonia in Santiago, Chile. Chest 2014; 145: 290-6.

19. Sociedad Chilena de Enfermedades Respiratorias y Sociedad Chilena de Infectología. Manejo de la neumonía del adulto adquirida en la comunidad. Resumen del consenso nacional. Rev Med Chile 2005; 133: 953-67.

20. Mandell LA, Wunderink RG, Anzueto A, Bartlett JG, Campbell GD, Dean NC, et al; Infectious Diseases Society of America; American Thoracic Society. Infectious Diseases Society of America/American Thoracic Society consensus guidelines on the management of community-acquired pneumonia in adults. Clin Infect Dis 2007; 44 (Suppl 2): S27-72.

21. Lim WS, Baudouin SV, George RC, Hill AT, Jamieson C, Le Jeune I, et al. Pneumonia Guidelines Committee of the British Thoracic Society Standards of Care Committee. British Thoracic Society guidelines for the management of community acquired pneumonia in adults: update 2009. Thorax 2009; 64 (Suppl 3): 1-55.

22. Bantar C, Curcio D, Jasovich A, Bagnulo H, Arango A, Bavestrello L, et al. Neumonía aguda adquirida en la comunidad en adultos: Actualización de los lineamientos para el tratamiento antimicrobiano inicial basado en la evidencia local del Grupo de Trabajo de Sudamérica (ConsenSur II). Rev Chil Infectol 2010; 27 (Suppl 1): S9-S38.

23. Chan YR, Morris A. Molecular diagnostic methods in pneumonia. Curr Opin Infect Dis 2007; 20: 157-64.

24. Nolte FS. Molecular diagnostics for detection of bacterial and viral pathogens in community-acquired pneumonia. Clin Infect Dis 2008; 47 (Suppl 3): S123-6. 
25. Fang GD, Fine M, Orloff J, Arisumi D, Yu VL, Kapoor $\mathrm{W}$, et al. New emerging etiologies for community-acquired pneumonia with implications for therapy. A prospective multicenter study of 359 cases. Medicine (Baltimore) 1990; 69: 307-16.

26. Baron E, Murray P. Bacteriology. In: Murray P, Baron E, Pfaller M, Tenover F, Yolken R, eds. Manual of Clinical Microbiology. Washington DC: ASM Press, 1999; 246821.

27. Clinical and Laboratory Standards Institute. Performance standards for antimicrobial susceptibility testing: $18^{\text {th }}$ informational supplement. CLSI document M100-S18. Wayne, PA: Clinical and Laboratory Standards Institute, 2008.

28. Fine MJ, Auble TE, Yealy DM, Hanusa BH, Weissfeld LA, Singer DE, et al. A prediction rule to identify lowrisk patients with community-acquired pneumonia. $\mathrm{N}$ Engl J Med 1997; 336: 243-50.

29. Lim WS, Van Der Eerden MM, Laing R, Boersma WG, Karalus N, Town GI, et al. Defining community acquired pneumonia severity on presentation to hospital: an international derivation and validation study. Thorax 2003; 58: 377-82.

30. Jain S, Self WH, Wunderink RG, Fakhran S, Balk R, Bramley AM, et al. Community-acquired pneumonia requiring hospitalization among U.S. adults. $\mathrm{N}$ Engl J Med 2015; 373: 415-27.

31. Wu X, Wang Q, Wang M, Su X, Xing Z, Zhang W, et al. Incidence of respiratory viral infections detected by PCR and real-time PCR in adult patients with commu- nity-acquired pneumonia: A meta-analysis. Respiration 2015; 89: 343-52.

32. Farr BM, Kaiser DL, Harrison BD, Connolly CK. Prediction of microbial aetiology at admission to hospitalfor pneumonia from the presenting clinical features. British Thoracic Society Pneumonia Research Subcommittee. Thorax 1989; 44: 1031-5.

33. Ruiz M, Ewig S, Marcos MA, Martínez JA, Arancibia F, Mensa J, et al. Etiology of community-acquired pneumonia: impact of age, comorbidity, and severity. Am J Respir Crit Care Med 1999; 160: 397-405.

34. Macfarlane J, Holmes W, Gard P, Macfarlane R, Rose $\mathrm{D}$, Weston V, et al. Prospective study of the incidence, aetiology and outcome of adult lower respiratory tract illness in the community. Thorax 2001; 56: 109-14.

35. Sopena N, Pedro-Botet ML, Sabrià M, García-Parés D, Reynaga E, García-Núñez M. Comparative study of community-acquired pneumonia caused by Streptococcus pneumoniae, Legionella pneumophila or Chlamydia pneumoniae. Scand J Infect Dis 2004; 36: 330-4.

36. Beovi B, Bonac B, Kese D, Avsic-Zupanc T, Kreft S, Lesnicar G, et al. Aetiology and clinical presentation of mild community-acquired bacterial pneumonia. Eur J Clin Microbiol Infect Dis 2003; 22: 584-91.

37. Falsey AR, Walsh EE. Viral pneumonia in older adults. Clin Infect Dis 2006; 42: 518-24.

38. Jennings LC, Anderson TP, Beynon KA, Chua A, Laing RT, Werno AM, et al. Incidence and characteristics of viral community-acquired pneumonia in adults. Thorax 2008; 63: 42-8. 